\title{
Cardiac evaluation of Covid-19 patients with post-discharge dyspnoea
}

\author{
Panda 5. ${ }^{1 *}$, Kumar Sharma S. ${ }^{2}$ \\ DOI: https://doi.org/10.17511/ijmrr.2020.i06.11 \\ 1* Sibaram Panda, Assistant Professor, Department of Cardiology, Veer Surendra Sai Institute Of Medical Sciences And Research, Burla, \\ Orissa, India. \\ 2 Sunil Kumar Sharma, Professor and Head, Department of Cardiology, Veer Surendra Sai Institute Of Medical Sciences And Research, \\ Burla, Orissa, India.
}

Background: Dyspnoea is one of the common symptoms in COVID-19 patients after discharge from the hospital. So evaluation of cardiac function becomes necessary in COVID patients after hospital discharge. AIM: To study the cardiac function of COVID 19 patients presenting with dyspnoea after discharge from hospital within 3 months of symptom onset. Materials and methods: 245 posthospital discharge COVID-19 patients enrolled in the study. The patients with abnormal echocardiography are further divided into three groups, A) patients with $P A H \pm R V D, B$ ) patients with LV diastolic dysfunction C) patients with LV systolic dysfunction. Data of the three groups were compared. Results: Out of 245 patients, 64\% (157) patients show abnormal echocardiogram.75 (30.6\%) patient show PAH $\pm R V D, 61(24.8 \%)$ patients shows LV diastolic dysfunction and $21(8.57 \%)$ patients shows LV systolic dysfunction. patients with ventricular dysfunction significantly associated with multiple risk factors and comorbidity. Grade $1,2,3,4$ diastolic dysfunction seen in $27.8 \%, 34.4 \%, 29.5 \%, 8.1 \%$ in group B respectively. LV systolic dysfunction is mild in $13(61.9 \%)$, moderate in $6(28.5 \%)$, severe in $1(4.7 \%)$ in group C patients. Ntprobnp, tropnin significantly higher in all groups. Also, CRP, D dimer significantly higher in group A, but non significantly higher in group B, C. Conclusion: RV dysfunction is the most common pattern seen in around $30 \%$ of patients. LV diastolic dysfunction is not uncommon, seen in $1 / 4$ the patients. Patients with cardiac dysfunction have a high level of cardiac and inflammatory biomarkers, which can lead to grievous cardiovascular complications. So close follow up required.

Keywords: Dyspnoea, COVID, PAH with RV dysfunction, Systolic dysfunction, Diastolic dysfunction

Corresponding Author

Sibaram Panda, Assistant Professor, Department of Cardiology, Veer Surendra Sai Institute Of Medical Sciences And Research, Burla, Orissa, India. Email: drsibaram@gmail.com

\section{How to Cite this Article}

Panda S, Sharma SK. Cardiac evaluation of Covid-19 patients with post-discharge dyspnoea. Int J Med Res Rev. 2020;8(6):434-439.

Available From

https://ijmrr.medresearch.in/index.php/ijmrr/article/ view/1228
To Browse

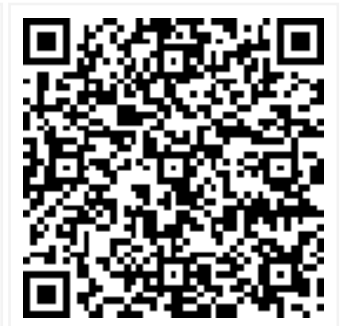

Manuscript Received 2020-11-18

Conflict of Interest No
Review Round 1 2020-11-28

Nil
Review Round 2 2020-12-07

Ethical Approval Yes
Review Round 3

Plagiarism X-checker $5 \%$
Accepted 2020-12-18

Note an Open Access article licensed under a Creative Commons Attribution 4.0 International License https://creativecommons.org/licenses/by/4.0/ unported [CC BY 4.0]. 


\section{Introduction}

There is nothing in the universe more important than our life. To date, about 1.2 million people lost their life due to the Covid-19 virus. The person who survived from Covid-19 pneumonia feels very lucky. On the other hand Covid-19 viruses imposing their footprints in the heart and lungs of humans silently. Because the main entrance for the Covid-19 cycle starts with the ACE2 receptor, which is present on the surface arterial endothelial cell and smooth muscle cell of virtually all organs, most commonly lungs and heart [1]. ACE2 receptor-mediated pathway provokes a volcano of inflammation which causes endothelial dysfunction, lung coagulopathy, and microthrombi, and it ultimately leads to secondary hemodynamic changes in pulmonary vasculature and $\mathrm{PAH}$. Direct viral damage, aggravation of systemic inflammatory response, microthrombi, hypoxemia, and increased afterload may all contribute to cardiac dysfunction [2].

So, it seems quite natural that a significant number of patients have persistent symptoms of dyspnoea and fatigability after discharge from the hospital. A recent Italian study shows $43 \%$ of patients presented with dyspnoea after the acute phase of the disease [3]. In another study, $48.4 \%$ of patients who recovered from the acute covid period have dyspnoea [4]. Although the outcomes of patients surviving Covid-19 pneumonia is unknown, these patients have to suffer serious cardiac sequelae like ventricular dysfunction, $\mathrm{PAH}$, arrhythmia after hospital discharge. So, in the above circumstances, it becomes extremely necessary to evaluate ventricular function in COVID patients presenting with dyspnoea after hospital discharge.

\section{Materials and Methods}

Type of study: Prospective, Longitudinal, Casecontrol study

Place of the study: VIMSAR, Burla, Orissa

Period of study: 21st April 2020 to 21st October 2020.

Inclusion criteria: COVID 19 patients presenting with dyspnoea after discharge from the hospital and within 3 months of symptom onset

Exclusion criteria: Patient with a documented previous history of corpulmonale, PAH due to any etiology, AMI, cardiomyopathy, or valvular heart disease.
A total of 245 Patient COVID19 patients with the above selection criteria enrolled. Risk factors like hypertension, diabetes, smoking, dyslipidemia, obesity, history of diseases CKD/ COPD/ PAD, and history of non-invasive /invasive ventilation taken. ECG, chest XRAY, biomarkers of patients done along with routine laboratory test. All patients are routinely sent for echocardiography. Echocardiography is done with personal protection equipment according to current WHO standards and local institutional protocols, including FFP2 mask or equivalent, double gowns, double pair gloves, and eye protection goggles. RV function ( $R V$ basal diameter, TAPSE, FAC, AT), LV function (EF, LVEDD, LVESD, LVS' velocity, $E$ velocity, A velocity, E/A ratio, lateral $e^{\prime}$ velocity, septale' velocity, lateral $E / e^{\prime}$ ratio) measured $[5,6,7]$. The patients with abnormal echocardiography are further divided into three groups A) patients with $P A H \pm R V D, B$ ) patients with LV diastolic dysfunction C) patients with LV systolic dysfunction. Data's of three groups compared statistically with data of patients with patients normal echocardiography.

Statistical analysis: Mean with standard deviation or proportion of a group compared with a control group to derive $\mathrm{p}$-value. $\mathrm{P}$ value $<0.005$ is significant.

Ethical approval: Ethical clearance taken from the ethical committee.

\section{Results}

Out of 245 patients, 64\% (157) patients show abnormal echocardiogram.30.6\% (75) patients have $\mathrm{PAH} \pm \mathrm{RVD}, 61(24.8 \%)$ patients found to have LV diastolic dysfunction and $21(8.57 \%)$ patients have LV systolic dysfunction (Figure 1 ).

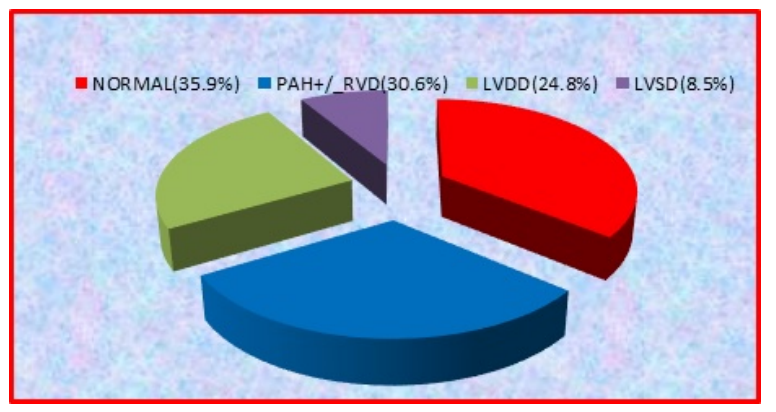

Fig-1: Distribution of echocardiographic pattern.

2) Patients with ventricular dysfunction are more significantly associated with risk factors and comorbidities. 
However, the history of NIV or invasive ventilation during hospitalization is significantly higher ( $p$ value $<0.006$ ) in group $A$. (Table 1).

Table-1: Comparison of baseline characteristics.

\begin{tabular}{|l|l|l|l|l|l|l|l|}
\hline & \multicolumn{1}{|c|}{ Normal } & \multicolumn{1}{|c|}{ PAH \pm RVD } & \multicolumn{1}{|c|}{ P value } & \multicolumn{1}{|c|}{ LVDD } & P value & \multicolumn{1}{|c|}{ LVSD } & P Value \\
\hline Age(years) & $63.2 \pm 17$ & $71.3 \pm 8$ & 0.0013 & $69.2 \pm 18$ & 0.004 & $68.2 \pm 16$ & 0.22 \\
\hline Male Sex & $61(69.3)$ & $51(68)$ & 0.429 & $43(70.4)$ & 0.44 & $15(71.4)$ & 0.42 \\
\hline BMI $(\mathrm{kg} / \mathrm{m} 2)$ & $25.7 \pm 0.8$ & $27.5 \pm 0.8$ & $<0.001$ & $27.1 \pm 0.7$ & $<0.0001$ & $26.9 \pm 0.7$ & $<0.001$ \\
\hline Smoking & $10(11.3)$ & $24(32)$ & 0.0059 & $17(27.8)$ & 0.05 & $6(28.5)$ & 0.022 \\
\hline Dyslipidaemia & $12(13.6)$ & $29(38.6)$ & 0.00016 & $20(32.7)$ & 0.0026 & $7(33.3)$ & 0.0016 \\
\hline Hypertension & $19(2.15)$ & $36(48 \%)$ & 0.00018 & $24(39.3)$ & 0.009 & $7(33.3)$ & 0.12 \\
\hline Diabetes mellitus & $10(11 \%)$ & $24(32 \%)$ & 0.0004 & $22(36.1)$ & 0.0001 & $8(38.0)$ & 0.004 \\
\hline PAD & $4(4.51 \%)$ & $9(1.2 \%)$ & 0.038 & $8 .(13.1)$ & 0.02 & $3(14.2)$ & 0.050 \\
\hline CKD & $6(6.8)$ & $13(17.3)$ & 0.018 & $11(14.6)$ & 0.015 & $4(19.0)$ & 0.040 \\
\hline COPD & $7(7.9 \%)$ & $14(18.6)$ & 0.020 & $10(16.3)$ & 0.0559 & $3(14.2)$ & 0.183 \\
\hline Use of NIV or invasive ventilation & $3(3.4 \%)$ & $21(28.1)$ & $<0.0061$ & $4(6.5)$ & 0.379 & $2(9.5)$ & 0.2315 \\
\hline
\end{tabular}

Numbers in the above table signifies mean and standard deviation or proportion $\mathrm{n} / \mathrm{N}(\%)$ or $\mathrm{p}$-value

75 (30.6\%) patients out of 245 patients have PASP more than $36 \mathrm{~mm}$ hg. Among patient with PAH with RV dysfunction, $F A C<35 \%$ found in $51(68 \%)$ patients, TAPSE $<17 \mathrm{~mm}$ found in 41 (54.6\%) patients. Acceleration time less than $100 \mathrm{msec}$ seen in $39(52 \%)$ patients in group $A$.
RV dilated in 58 (77 \%) patients in group A. Diastolic dysfunction seen in $24.8 \%$ patients. Grade $1,2,3,4$ diastolic dysfunction seen in $27.8 \%, 34.4 \%$, $29.5 \%, 8.1 \%$ patients in group B respectively. 46 $(75.4 \%)$ patients in group $\mathrm{B}$ have $\mathrm{E} / \mathrm{e}^{\prime}$ ratio $>14$. Mild, moderate, severe LV systolic dysfunction seen $61 \%, 28.5 \%, 9.5 \%$ in group C respectively (Table 2 ).

Table-2: Pattern of cardiac dysfunction in different groups.

\begin{tabular}{|c|c|c|c|c|c|c|c|c|c|}
\hline \multicolumn{10}{|c|}{ Assessment of PAH and RV function } \\
\hline $\begin{array}{l}\text { RV and PAH } \\
\text { parameter }\end{array}$ & $\begin{array}{l}\text { RV size dilated } \\
(\text { RVEDD }>41 \mathrm{~mm})\end{array}$ & $\left|\begin{array}{l}\text { FAC } \\
(<35 \%)\end{array}\right|$ & $\begin{array}{l}\text { TAPSE }(<17 \\
\mathrm{mm})\end{array}$ & $\begin{array}{l}\text { AT }(<100 \\
\mathrm{msec})\end{array}$ & $\mid \begin{array}{l}\text { IVC } \\
\text { dilated }>21 \mathrm{~mm}\end{array}$ & $\begin{array}{l}\text { PA dilated (>25 } \\
\text { mm) }\end{array}$ & $\begin{array}{l}\text { RA dilated } \\
(>18 \mathrm{~cm} 2)\end{array}$ & TR grading & \\
\hline \multirow{3}{*}{$\begin{array}{l}\text { Number of } \\
\text { patients (\%) }\end{array}$} & \multirow[t]{3}{*}{$58(77)$} & \multirow[t]{3}{*}{$51(68 \%)$} & \multirow[t]{3}{*}{$41(54.6)$} & \multirow[t]{3}{*}{$39(52)$} & \multirow[t]{3}{*}{$39(52)$} & \multirow[t]{3}{*}{$43(57.3 \%)$} & \multirow[t]{3}{*}{$34(45 \%)$} & Mild & $31(41)$ \\
\hline & & & & & & & & Moderate & $37(49)$ \\
\hline & & & & & & & & Severe & $7(9.3)$ \\
\hline \multicolumn{10}{|c|}{ Assessment LV diastolic function } \\
\hline \multicolumn{2}{|l|}{ Severity } & \multicolumn{2}{|l|}{ Grade 1} & \multicolumn{2}{|l|}{ Grade 2} & \multicolumn{2}{|l|}{ Grade 3} & \multicolumn{2}{|l|}{ Grade 4} \\
\hline Number of pat & s (\%) & \multicolumn{2}{|l|}{$17(27.8)$} & \multicolumn{2}{|l|}{$21(34.4 \%)$} & \multicolumn{2}{|l|}{$18(29.5 \%)$} & \multicolumn{2}{|l|}{$5(8.1)$} \\
\hline \multicolumn{10}{|c|}{ Assessment of LV systolic function } \\
\hline \multicolumn{2}{|l|}{ Severity } & & \multicolumn{3}{|c|}{ Number of patients (\%) } & \multicolumn{2}{|l|}{ Pattern } & \multicolumn{2}{|c|}{ Number of patients (\%) } \\
\hline \multicolumn{2}{|l|}{ Mild } & & \multicolumn{3}{|l|}{$13(61.9)$} & \multicolumn{2}{|l|}{ RWMA } & \multicolumn{2}{|l|}{$14(66.6)$} \\
\hline \multicolumn{2}{|l|}{ Moderate } & & $6(28.5)$ & & & Global hypokines & & $7(33.3)$ & \\
\hline Severe & & & $1(4.7)$ & & & & & & \\
\hline
\end{tabular}

Numbers in the above table signifies proportion $n / N(\%)$.

NTPROBNP, tropnin significantly higher in all groups. Also, CRP, D dimer significantly higher in group A, but non significantly higher in group B, C (Table 3).

Table-3: Comparison of biomarker association with each group.

\begin{tabular}{|l|l|l|l|l|l|l|l|}
\hline & \multicolumn{1}{|c|}{ NORMAL } & \multicolumn{1}{|c|}{ PAH+/_RVD } & \multicolumn{1}{c|}{ P value } & \multicolumn{1}{c|}{ LVDD } & \multicolumn{1}{c|}{ P value } & \multicolumn{1}{c|}{ LVSD } & \multicolumn{1}{c|}{ P value } \\
\hline D DIMER $(\mathrm{ng} / \mathrm{ml})$ & $389 \pm 123$ & $1400 \pm 886$ & $<0.001$ & $440 \pm 213$ & 0.668 & $44.2+240$ & 0.0870 \\
\hline TROPNIN I $(\mathrm{ng} / \mathrm{ml})$ & $124 \pm 86$ & $884+332$ & $<0.001$ & $1230+880$ & $<0.001$ & $3400 \pm 800$ & $<0.001$ \\
\hline CRP $(\mathrm{mg} / \mathrm{l})$ & $23.2+8.6$ & $55+18.6$ & $<0.0001$ & $24.1 \pm 08$ & 0.523 & $28 \pm 8.6$ & 0.0235 \\
\hline
\end{tabular}




\begin{tabular}{|l|l|l|l|l|l|l|l|}
\hline NTPROBNP $(\mathrm{pg} / \mathrm{ml})$ & $442 \pm 180$ & $4200 \pm 840$ & $<0.0001$ & $1800 \pm 732$ & $<0.001$ & $4800 \pm 3020$ & $<0.0001$ \\
\hline
\end{tabular}

Numbers in the above table signifies mean standard deviation or $\mathrm{p}$-value

ST-T changes the most common abnormality seen in $29 \%$ of patients with LV or RV dysfunction. AF is seen in $21 \%$ of patients. Prolonged PR interval, QT prolongation seen in $3 \%, 2 \%$ patients respectively.

\section{Discussion}

There is scanty data regarding the post-recovery COVID period, as the COVID pandemic is not over. Most of the existing studies were done in hospitalized COVID patients. Wherever the present study includes patients within a post-recovery period after discharge from the hospital and within 3 months of symptom onset.

Out of 245 patients, around 2/3 of rd patients show ventricular dysfunction. Around $30.6 \%$ of patients show $P A H \pm R V D$, around $1 / 4$ th shows LV diastolic dysfunction, and $8.57 \%$ of patients show LV systolic dysfunction. Szekelyetal found in his study that $39 \%$ of patients have RV dilation with or without RV dysfunction and16 \% have LV diastolic dysfunction, $10 \%$ have LV systolic dysfunction. 8 However this study was conducted in hospitalized patients within 24 hours of admission. The present study includes patients after discharge within 3 months of symptom onset. persisting myocardial inflammation may be a cause for the slowly progressive development of new-onset LV dysfunction.

Patients with PAH group are significantly older as compared to other groups and more frequently associated risk factors like hypertension $(p=0.00018)$, diabetes $(p=0.0004)$, dyslipidemia $(p=0.0016)$, smoking $(p=0.0059)$. The more frequent risk factor associated with this group is hypertension $(48 \%)$ ), dyslipidemia (38.6\%) diabetes (32\%). Richardson-et al studied COVID patients in a hospital in Italy and found that patients with PAH are more frequently associated with hypertension $(56.6 \%)$, obesity $(41.7 \%)$, diabetes (33.8\%) [9]. Also, patients with the PAH group were significantly associated with a history of NIV or invasive ventilation. Pagnesi-et al studied COVID patients innonICU setup, where he found that patients with PAH more frequently required NIV during hospitalization as compared to patients without PAH [10].
Among patient in group A with RV dysfunction, more common echocardiographic pattern is globally reduced RV function (i.e. $\mathrm{FAC}<35 \%$ ) in $51(68 \%)$ patients than longitudinally reduced $\mathrm{RV}$ function (i.e. TAPSE $<17 \mathrm{~mm})$ in $41(54.6 \%)$ patients. RV dilated in $58(77 \%)$ patients in group A and overall in $23.6 \%$ of total patients. However, Szekely-et al reported RV enlargement in $40 \%$ of patients.

But this study was conducted in covid patients within 24 hours of admission not excluding preexisting heart disease [8]. Moody-et al observed in hospitalized COVID 19 pneumonia patients and found out that, $38 \%$ of patients have RV dilated,35\% of patients have RV dysfunction [11]. RV dysfunction seen in COVID pneumonia patients can be due to increased afterload, hypoxemia, microthrombi, and direct myocardial injury. However, around $1 / 4$ th of patients presented with diastolic dysfunction. Around 2/3rd patients in group $B$ have either grade 2 or grade 3 diastolic dysfunction. $46(75.4 \%)$ patients in group B have $\mathrm{E} / \mathrm{e}^{\prime}$ ratio $>14$. Szekely et al studied hospital admitted Covid-19 patients and found diastolic dysfunction in $16 \%$ of patients [8].

However, one CMR study revealed that ongoing myocardial inflammation in $60 \%$ of Covid-19 recovered patients [12]. Ongoing inflammation can be a cause for the increased incidence of diastolic dysfunction in the present study. Diastolic dysfunction can also be due to cardiac fibrosis, microvascular ischemia due to intravascular coagulation, and hypoxemia also to direct viral infiltration, inflammation.

$8.5 \%$ of patients developed LV systolic dysfunction, out of which around $90 \%$ patients mild to moderate LV dysfunction. In Szekely et al study, LV systolic dysfunction found $10 \%$ of hospitalized Covid-19 patients. However above study not excluded preexisting heart disease in patients [8]. Interestingly $14(66.6 \%)$ patients have MI with RWMA in echocardiographic finding and $7(33 \%)$ patients global hypokinesia. but patients presented with MI have no history of pre-existing MI before COVID infection.

Most of these patients have a high level of D-dimer and CRP in addition to troponin. In a study, it is seen that D-dimer invariably elevated in all COVID patients with STEMI, which is coincidental to our finding [13]. 
In the above scenario in COVID patients, Microemboli, micro-vascular coronary dysfunction, hypercoagulability, plaque rupture due to inflammation may be pathophysiologic factors to cause AMI. Nt-probnp, tropnin significantly higher in all groups.

Also, CRP, D dimer significantly higher in the PAH group, but non significantly higher in the LV dysfunction group. Pagnesietal found in hospitalized COVID patients that, PAH significantly associated with higher-level d dimer, ntprobnp, and RV dysfunction significantly with a higher level of troponin, ntprobnp only [10].

Szekely-et al seen in their study that, patient with a high level of $E / e^{\prime}$ ratio (implies worse diastolic dysfunction), significantly associated with the high level of troponin [8].

\section{Limitation}

A study conducted on a limited number of patients. The study was done only during the presentation. Further, follow-up is required. Other pulmonary causes of dyspnoea are not taken into account.

\section{Conclusion}

Dyspnoea is one of the most common symptoms, which cannot be ignored in post-discharge COVID patients. Cardiac dysfunction is seen in around $2 / 3$ of patients. RV dysfunction is the most common pattern seen in around $30 \%$ of patients. However, LV diastolic dysfunction is not uncommon, seen in $1 / 4$ th patients. LV systolic dysfunction less common, seen in less than $10 \%$ of patients.

Severe LV dysfunction is rare. High level of the cardiac and inflammatory biomarker in these groups of patients, which can lead to cardiovascular complications in the future post COVID era. So COVID Patients with cardiac dysfunction after discharge cannot be ignored the close follow up required to avoid cardiovascular complication in both COVID and post COVID.

\section{What does this study add to existing knowledge?}

Although the prevalence of PAH is decreased a bit, the prevalence of high-grade diastolic dysfunction is enormously evolving during the post-discharge COVID period.
Although the outcome of diastolic dysfunction is unknown, however patient in the long run can progress to systolic dysfunction as a result of ongoing viral inflammation and fibrosis. On the other hand, residual $\mathrm{PAH}$ also contributes to the issue. Inclusion of inflammatory biomarkers in addition to cardiac evaluation is essential. If at all COVID pandemic will over, COVID inflammation will not leave us so easily and it may cause unpredictable complications like CVA, deep vein thrombosis, arrhythmia, pulmonary embolism, heart failure imposing a tremendous impact on morbidity and mortality of COVID patients on the long term.

\section{Author's contribution}

Dr. Sibaram Panda: Primary investigator of the study, Literature Survey, Data Analysis, Paper Writing

Dr. Sunil Kumar Sharma: Helped to get data for manuscript preparation, Study design, and supervising.

\section{Reference}

01. Hamming I, Timens W, Bulthuis ML, Lely AT, Navis GV, van Goor $H$. Tissue distribution of ACE2 protein, the functional receptor for SARS coronavirus- A first step in understanding SARS pathogenesis. J Pathol. 2004;203(2)631-637. doi:10.1002/path.1570 [Crossref]

02. Potus F, Mai V, Lebret $M$, Malenfant S, BretonGagnon E, Lajoie AC, Boucherat O, Bonnet S, Provencher $S$. Novel insights on the pulmonary vascular consequences of COVID-19. Am J Physiol-Lung Cell Molecular Physiol. 2020;319(2)L277-L288. doi:10.1152/ajplung.00195.2020

[Crossref]

03. Wise J. Covid-19- Symptoms are common after acute phase of disease. Italian study shows. doi: 10 .

1136/bmj.m2804 [Crossref]

04. Carfi A, Bernabei R. Landi FGemelli Against COVID-19 Post-Acute Care Study Group, for the Gemelli Against COVID-19 Post-Acute Care Study Group- Persistent symptoms in patients after acute Covid-19. JAMA. 2020;324(6)603605.

doi:10.1001/jama.2020.12603 [Crossref] 
05. Arcasoy SM, Christie JD, Ferrari VA, Sutton MS, Zisman DA, Blumenthal NP, Pochettino A, Kotloff RM. Echocardiographic assessment of pulmonary hypertension in patients with advanced lung disease. Am J Resp Critical Care Med. 2003;167(5)735-740.

doi: $10.1503 /$ erp-17-0071 [Crossref]

06. Nagueh SF, Smiseth OA, Appleton CP, Byrd BF, Dokainish $H$, Edvardsen $T$, et al. Recommendations for the evaluation of left ventricular diastolic function by echocardio graphy- an update from the American Society of Echocardiography and the European Association of Cardiovascular Imaging. European J Echocardiograph. 2016;17(12)1321-60.

doi: 10.1016/j.echo.2016.01.011 [Crossref]

07. Zerbib Y, Maizel J, Slama M. Echocardiographic assessment of left ventricular function. JECCM. $2019 ; 3$.

doi: $10.21037 /$ jeccm.2019.07.05 [Crossref]

08. Szekely Y, Lichter Y, Taieb P, Banai A, Hochstadt A, Merdler I, et al. The Spectrum of Cardiac Manifestations in Coronavirus Disease 2019 (COVID-19)-a Systematic Echocardiographic Study. Circulation. 2020;142(4)342-353.

doi: 10.1161/circulationaha.120.047971 [Crossref]

09. Richardson S, Hirsch JS, Narasimhan M, Crawford JM, McGinn T, Davidson KW, et al. Presenting characteristics, comorbidities, and outcomes among 5700 patients hospitalized with COVID-19 in the New York City area. JAMA. 2020;323(20)2052-2059 doi: 10.

1001/jama.2020.6775 [Crossref]
10. Pagnesi $M$, Baldetti $L$, Beneduce $A$, Calvo $F$, Gramegna M, Pazzanese $V$, et al. Pulmonary hypertension and right ventricular involvement in hospitalised patients with COVID-19. Heart. 2020;106(17)1324-1331.

doi: 10.1136/heartjnl-2020-317355 [Crossref]

11. Moody WE, Mahmoud-Elsayed HM, Senior J, Gul $U$, Khan-Kheil AM, Horne $S$, et al. Impact of Right Ventricular Dysfunction on Mortality in Patients Hospitalized with COVID-19 according to Race. CJC open. 2020. doi: 10.1016?j.cjco.2020.09.016 [Crossref]

12. Puntmann VO, Carerj $M L$, Wieters I, Fahim $M$, Arendt C, Hoffmann J, et al. Outcomes of cardiovascular magnetic resonance imaging in patients recently recovered from coronavirus disease 2019 (COVID-19). JAMA Cardiol. 2020;5(11)1265-1273.

doi: 10.1001/jama cardio.2020.3557 [Crossref]

13. Bangalore $S$, Sharma A, Slotwiner A, Yatskar L, Harari R, Shah B, et al. ST-segment elevation in patients with Covid-19-a case series. N Eng J Med. 2020;382(25)2478-2480.

doi:10.1056/NEJMc20009020 [Crossref] 